\title{
Trangressões canônicas: Queerizando as donzelas-guerreiras
}

\author{
Helder Thiago Maia \\ Universidade de São Paulo
}

Resumo: Neste artigo, analiso o paradigma literário das donzelas-guerreiras, assim como o uso que a crítica literária tem feito deste paradigma. Além disso, proponho uma leitura queer dessas personagens, seja a partir da ideia de masculinidades dissidentes, seja a partir da ideia de que a transição entre gêneros é parte da diversidade humana, o que nos afasta de leituras psicanalíticas que entendem as dissidências e os trânsitos entre gêneros como patologia e/ou desenvolvimento incompleto. Por acreditar que há um uso exagerado do termo para ler diferentes dissidências literárias de gênero, proponho também o desdobramento do paradigma das donzelas-guerreiras em quatro outros paradigmas: as mulheres masculinas, as mulheres guerreiras, as donzelas-guerreiras e as transgeneridades guerreiras.

Palavras-chave: Literatura comparada, donzela-guerreira, teoria queer

\begin{abstract}
In this article, I analyze the literary paradigm of donzelas-guerreiras, as well as the use that literary criticism has made of this paradigm. In addition, I propose a queer reading of these characters, either from the idea of dissident masculinities, or from the idea that the transition between genders is part of human diversity, which separates us from the psychoanalytic readings that understand the dissidents and the transits between the genders like pathology and / or incomplete development. Because I believe there is an over-use of the paradigm to read different literary dissidents of gender, I also propose the unfolding of the paradigm of the donzela-guerreira in four other paradigms: male women, women warriors, maiden warrior and transgender warriors.
\end{abstract}

Keywords: Comparative literature, donzela-guerreira, queer theory 


\section{Notas Históricas e Literárias sobre as Donzelas-Guerreiras}

A donzela-guerreira é um paradigma da literatura mundial que tem servido como base, padrão e modelo para a criação de muitas narrativas. De acordo com Valdeci Oliveira (2001: 133), a donzela-guerreira é um "motivo literário" que possui um enredo com forte coesão interna e um ethos específico, o que não só tem permitido que a personagem faça constantes reaparições na literatura, garantindo uma forte presença no imaginário da cultura ocidental, como também a torna facilmente reconhecível. Não estamos incidindo em um erro ou simples exagero quando falamos em "paradigma da literatura mundial" ou "imaginário da cultura ocidental"; como mostraremos, a donzela-guerreira é parte tanto da narrativa ocidental quanto oriental, tendo atravessado diferentes países e tempos históricos.

No entanto, ela não é somente um paradigma literário, mas é também uma figura histórica, o que significa, como argumenta Vania Vasconcelos (2010: 249), que donzelasguerreiras "de carne e osso" circularam e são parte da história de diferentes países. Nesse sentido, permitindo-se algum exagero, Walnice Galvão (1998: 82), a mais importante pesquisadora e crítica literária brasileira sobre este assunto, diz que a donzela-guerreira aparece com tal profusão na história e na literatura que talvez fosse difícil se ter notícia de uma guerra sem a participação de uma donzela-guerreira.

Do ponto de vista histórico, e utilizando a ideia de donzela-guerreira de forma bastante restrita, estamos falando, por exemplo, dx viking Guerreiro Birka (século X), dxs francesxs $^{1}$ Joana d'Arc (1412-1431) e Louise Labé/Capitão Loyz (1524-1566), dxs espanholas/espanhóis Elana/Eleno de Céspedes (1545-?), Catalina/Antonio de Erauso (1592-1650) e María Pérez/La varona de Castilha (século XI), dxs inglesxs Mary/Mark Read (1690-1721) e Mary Anne Talbot/John Taylor (1778-1808), dx norte-americanx Lucy/George Baker (séculos XVIII e XIX), dx russx Nadezhda Durova/Alexander Durov (1783-1866), dxs mexicanxs Amelia/Amelio Robles (1889-1984), Angel/Ángela Jiménez (1896-?) e Petra/Pedro Herrera (século XX), etc.

Assim como também estamos falando dx portuguesx Antónia/António Rodrigues (1580-?), militar da coroa portuguesa, conhecidx como "terror dos mouros" por conta das 
suas vitórias em Mazagão, atual Marrocos, dx angolanx Nzinga M'bandi (1583-1663), que lutou contra o domínio e a escravidão portuguesa, e dxs brasileirxs Maria Úrsula de Abreu e Lencastre/Baltazhar do Couto Cardoso (1682-?), que lutou por mais de doze anos pelo exército português na Índia Portuguesa, atual Goa, Maria Quitéria/Soldado Medeiros (17921853), que lutou nas guerras de independência do Brasil, e Maria Curupaiti (século XIX) e Jovita Feitosa (1848-1867), que lutaram na Guerra do Paraguai.

O maior levantamento de donzelas-guerreiras de "carne e osso" foi realizado por Rudolf Dekker e Van de Pol Lotte (2006), que catalogaram, conforme os autores, 119 casos de "travestimento feminino", especialmente na Holanda, Alemanha e Inglaterra, entre 1550 e 1839, dentre os quais podemos dizer que há quase noventa donzelas-guerreiras. Além disso, consideramos útil a metodologia do livro, por organizar essas vidas principalmente a partir do tempo de duração e do significado do trânsito entre gêneros para estes sujeitos. Nossa proposta de leitura das donzelas-guerreiras literárias está, portanto, em diálogo com este trabalho.

Do ponto de vista literário, de acordo com sistematização da pesquisadora Edilene Batista (2012, 2016), a primeira referência literária da donzela-guerreira é a popular balada chinesa, do século VI, Mulan ou Fá Mok Lan, de autoria desconhecida, que, em 1998, foi levada ao cinema pelos estúdios Disney e narra a participação da personagem na guerra contra os tártaros. No entanto, como aponta Ana Maria Amaro (1992: 52), a ode a Mulan é apenas a mais conhecida das donzelas-guerreiras chinesas, uma vez que, na China, há pelo menos quatro outras narrativas conhecidas.

Segundo Batista (2012, 2016), a segunda referência literária mais antiga é o poema medieval oral, de origem ibérica e de autoria anônima, Da donzela que vai à guerra, que, segundo Galvão (1998: 183) e Anabela Silva (2010: 51), remete a uma guerra entre Aragão e França. 0 poema, que é parte do romanceiro espanhol e português, aparece, pela primeira vez, de acordo com Walnice Vilalva (2004: 11) e Silva (2010: 52), nos livros Ulissypo (1618) e Aulegrafia (1619), de José Ferreira Vasconcelos. Posteriormente, foi documentado também por: José Maria Costa e Silva, que teria recolhido a história a partir de uma senhora em Goa, no livro Isabel ou a Heroína de Aragão (1832), de acordo com Amaro (1992: 64); 
Almeida Garret, no volume III do livro Romanceiro e Cancioneiro Geral (1851), de acordo com Batista (2010) e Silva (2010); Teófilo Braga, no livro Romanceiro Geral Português (1867), de acordo com Vilalva (2004: 10); e Ramón Menéndez Pidal, no livro Flor nueva de romances viejos (1928), de acordo com Amaro (1992: 51); o que indica, conforme sugere Vilalva (2004: 11), que o tema da donzela-guerreira foi um dos romances de maior circulação na península ibérica.

Por fim, nesse breve resumo histórico-literário da donzela-guerreira, a terceira referência, segundo Galvão (1998: 15), Oliveira (2001) e Batista (2012, 2016), são as donzelas-guerreiras de três escritores italianos. São elas: Marfisa, do livro Orlando Enamorado (1483), de Matteo Boiardo, Bradamanta, do livro Orlando Furioso (1516), de Ludovico Ariosto, e Clorinda, do livro Jerusalém Libertada (1581), de Torquato Tasso. No entanto, para além dessa breve cartografia, há também referências de donzelas-guerreiras na mitologia grega (Batista 2012: 278; Vilalva 2004: 7), em William Sheakespeare (Galvão 2002: 22; Gutiérrez 2010: 6), no teatro espanhol dos séculos XVI e XVII, em autores como Lope de Vega, Calderón de la Barca e Tirso de Molina (Silva 2010: 13; Mendieta 2017: 164; García Surrallés 1989: 16), e em poemas sefarditas do século XVI de Ben Mosé Najara (Silva 2010: 54; García Surrallés 1989: 6).

No Brasil, o paradigma da donzela-guerreira aparece primeiro através da literatura oral, que foram recolhidas, principalmente, segundo Galvão (1998: 189), Oliveira (2001: 40) e Vilalva (2004: 12), por Silvio Romero, no livro Estudos sobre a poesia popular do Brasil (1888), e Câmara Cascudo, no livro Contos tradicionais do Brasil (1946). No entanto, de acordo com Oliveira (2001), o tema da donzela-guerreira, em nossa história literária, aparece com mais frequência em prosa, com exceção de cordéis e dos poemas "Uma antepassada da donzela-guerreira", de Cecília Meireles, no livro de autoria múltipla Estudos e ensaios folclóricos em homenagem a Renato Almeida (1960), e "Mulher vestida de homem", do livro Menino Antigo (1973), de Carlos Drummond de Andrade. Nesse sentido, há uma série de livros, sobre os quais falaremos mais adiante, apontados por pesquisadoras brasileiras, que teriam donzelas-guerreiras em seus enredos. 


\section{Queerizando as Donzelas Guerreiras}

Partindo, principalmente, da balada chinesa e dos romances ibéricos, Vilalva (2004: 15) diz que as narrativas das donzelas-guerreiras se estruturam a partir de três momentos: a lamentação de um pai por não ter um filho que o represente na guerra, a filha que monta um estratagema para não ser reconhecida e se apresenta como guerreiro e a confirmação da identidade do guerreiro. Silva (2010: 19) resume a narrativa em quatro sequências: a problemática paterna, a androginização da donzela, as provas a que é submetido e o desfecho com "confirmação" da sua identidade. Carmen García Surrallés (1989: 8) diz que seis sequências mínimas resumem as donzelas-guerreiras: há uma guerra e um ancião se maldiz por não ter filho que possa ir em seu lugar, a filha se oferece para ir à guerra, a filha oculta as características femininas, o soldado vence na guerra, há uma desconfiança sobre sua identidade e, por fim, algum guerreiro se apaixona pelo soldado, que é de antemão apresentado ao leitor como uma donzela. Galvão (1998) e Eliana Silva (2013), com mais detalhes, assim resumem o paradigma da donzela-guerreira:

Sua posição é numinosa na série filial, como primogênita ou unigênita, às vezes a caçula; o pai não tem filhos homens adultos ou, o que é quase regra, não os tem de todo. Ela corta os cabelos, enverga trajes masculinos, abdica das fraquezas femininas [...], cinge os seios e as ancas, trata seus ferimentos em segredo, assim como se banha escondido. Costuma ser descoberta quando, ferida, o corpo é desvendado; e guerreia; e morre. (Galvão 1998: 12)

Em seu protótipo tradicional, a donzela guerreira costuma ser oriunda de uma família em que inexistem filhos homens ou estes são mais novos que ela. São frequentes também os casos em que é filha única ou, mais raramente, trata-se da caçula. A essa mulher se atribui o papel de defender o pai na guerra, uma vez que este se encontra fragilizado devido à idade avançada. Para tanto, a donzela guerreira precisa esconder suas peculiaridades femininas, trajando-se de homem e comportando-se como tal. Como símbolo dessa mudança, a donzela, normalmente, corta o cabelo, além de assumir o compromisso de não casar e permanecer virgem. Esses requisitos são indispensáveis para que a mesma mantenha resguardado seu segredo - ser uma mulher. (Silva 2013: 47)

De forma geral, portanto, primeiro a partir da própria literatura e depois da crítica literária, resumimos o paradigma da donzela-guerreira da seguinte forma: uma personagem 
que é entendida e narrada como uma mulher se apresenta para a guerra como homem e vive durante um período, geralmente longo, como homem, assumindo inclusive um nome masculino; exceto a família dessa personagem, nenhuma outra personagem sabe dessa transição entre gêneros, o segredo e a "descoberta" do trânsito entre gêneros são dois pontos importantes da narrativa; a personagem vai para a guerra, onde é reconhecida pela bravura; sexualmente é construído como virgem ou assexuado, o que serve para tranquilizar o leitor de que a transgressão de gênero, cuja motivação é patriótica, não implica uma transgressão sexual; na guerra, após ser ferido ou morto passa a ser entendido como uma mulher, o que normalmente serve para justificar a paixão de algum soldado pela personagem; a maioria daqueles que sobrevivem à guerra voltam a viver como mulher, alguns, entretanto, continuam a viver e ser reconhecidos como homens, mesmo após ser conhecido o trânsito entre gêneros.

Muito próximo da leitura de Oliveira (2001: 21), que diz que as duas características fundamentais das donzelas-guerreiras são a ocultação da identidade feminina e a aventura, nesta leitura, consideramos que dois são os traços fundamentais das donzelas-guerreiras: a experiência de um corpo designado como feminino que passa, sem que as outras personagens saibam desse trânsito, a viver e ser reconhecido socialmente como homem, 0 que algumas pesquisadoras chamam de "travestimento" ou "androgenização", e a experiência da guerra. Nesse sentido, apesar do nome donzela sugerir a virgindade dessas personagens, ou em último caso a sua assexualidade, entendemos, assim como Vilalva (2004: 173) e Tania Serra (Batista, 2016), que a virgindade, por conta das inúmeras variações na narrativa, não é uma característica que defina as donzelas-guerreiras.

Além disso, a partir de Eva Mendieta (2017) e Victor Rocha Monsalve (2005), acreditamos que o tópico da virgindade não só serviu para tranquilizar o leitor, ao mostrar que a transgressão de gênero não implicava uma vida sexualmente "devassa", como também visava, principalmente, aproximar a donzela-guerreira de um outro paradigma histórico e literário de tradição católica, o das "santas travestidas", que eram religiosas que viveram como homens por conta da sua fé. O paradigma das santas travestidas, através de um modelo, obviamente, hagiográfico, era não só bastante popular, como também era um 
produto "literário" de grande valor espiritual, estimulado, inclusive, pela Contrarreforma católica. Nesse sentido, a aproximação da donzelas-guerreiras às santas travestidas, através da virgindade, não só tornava as vidas reais e literárias das donzelas-guerreiras possíveis, como também construía narrativas de sacrifício para as mesmas. Para as santas travestidas viver como homem era um sacrifício pela fé, enquanto para as donzelas-guerreiras em um sacrifício pela pátria. ${ }^{2}$

Afastando-se um pouco mais das primeiras textualidades, consideramos que a fragilidade e a lei paterna não são um traço recorrente ou realmente significativo para a maior parte das donzelas-guerreiras, como também aponta Vilalva (2004: 97). Ademais, consideramos que a motivação e a experiência dessas personagens como homens e soldados não podem ser entendidas apenas como se fossem sujeitos sem autonomia, determinados e controlados pela lei paterna (Silva, 2013: 48), da mesma forma como entendemos que não se trata de uma falsa identidade (Batista, 2012: 280), de um mito que reforça o falogocentrismo (Batista, 2010), de uma representação da fantasia masculina (Freitas, 2012: 24), de mulheres que negam seu destino, de mulheres castradas que renunciam à própria identidade (Vasconcelos, 2010: 250), de mulheres mutiladas nos papeis que a natureza lhes oferece (Galvão 1998: 11; Sussekind 1984: 147), ou de mulheres com inveja do falo (Galvão 1998: 141).

Consideramos, ao contrário, assim como Jack Halberstam (2008: 94), que essas expressões de gênero não são uma imitação ou uma cópia de um gênero original que pertenceria exclusivamente aos corpos com falo. Consequentemente, entendemos não só que a masculinidade é um dispositivo biopolítico que interpela a todos como processo de subjetivação, mas também que a transição entre os gêneros é uma expressão da própria diversidade humana. Nesse sentido, essa psiquiatrização das diferenças com base em um modelo edípico, como podemos inferir a partir de Raewyn Connell (2003: 36), além de ser extremamente mecânico, e até mesmo anacrônico, toma apenas a masculinidade cisgênera e heterossexual ${ }^{3}$ como única forma de vida possível, ao mesmo tempo em que entende as masculinidades não-cisgêneras, as masculinidades femininas e as masculinidades gays como um desenvolvimento incompleto e/ou doença. 
Isto posto, acreditamos que, apesar das características que compõe as donzelasguerreiras serem bastante específicas, há um uso exagerado do conceito, muitas vezes tomado de modo metafórico, que tem servido para ler diferentes personagens que fogem ao padrão de feminilidade, que fogem, como argumenta Flora Sussekind (1984: 146), do destino habitual de seu sexo. Márcio Silva (2017: 226), por exemplo, chega a dizer que é possível uma donzela-guerreira que não só não tenha vivido como homem, mas que também não tenha ido à guerra, o que descaracteriza completamente o paradigma das donzelas-guerreiras e pouco acrescenta à análise crítica desses textos.

De forma semelhante, Galvão (1998: 174) sugere que Luzia-Homem (Olímpio 1993) é uma donzela-guerreira pela força descomunal e por ter cortado os cabelos, ainda que a mesma nunca tenha vivido como homem ou tenha ido à guerra, assim como Sussekind (1984: 122), que não só considera Luzia-Homem uma donzela-guerreira, como também argumenta o mesmo sobre Guidinha do Poço (Paiva 2000), alegando que ambas "fogem da vida do lar e da fragilidade feminina", ainda que nenhuma das duas tenha vivido a experiência do trânsito entre gêneros ou da guerra.

Apesar do uso indiferenciado que Galvão muitas vezes tem feito desse paradigma, consideramos, seguindo a Oliveira (2001: 125), que as donzelas-guerreiras possuem características singulares que as diferenciam de outras personagens que fogem das normatividades de sexo-gênero. Nesse sentido, essas experiências devem ser distinguidas, sob o risco de perdermos a potência que essas narrativas possuem de borrar as normatividades de sexo-gênero, assim como de silenciarmos tanto sobre as representações de vidas que transitam entres os gêneros, quanto sobre construções de masculinidades guerreiras a partir de sujeitos entendidos cisnormativamente como corpos sem falo.

Além disso, como argumenta Oliveira (2001: 126), se fossemos recorrer ao comportamento fora dos estereótipos da feminilidade como um elemento definidor da donzela-guerreira, poderíamos caracterizar como donzelas-guerreiras a maior parte das heroínas dos romances brasileiros. Por isso, o "viver como homem" e o "ir à guerra" não devem ser entendidos como metafóricos ou como sinônimos de mulheres masculinas, como em Luzia-Homem, ou de mulheres batalhadoras, como em Guidinha do Poço. 0 que o uso 
alargado do conceito tem feito é homogeneizar as personagens, ao mesmo tempo em que tem considerado o trânsito entre gêneros e as masculinidades de corpos considerados dissidentes como algo menor, incompleto, patológico, reafirmado, assim, a biologia como destino.

Nesse sentido, nossa perspectiva de leitura tem dois objetivos iniciais: queerizar a leitura da crítica literária sobre as donzelas-guerreiras, como também sugere Louise Vasvária (2006), mas, além disso, propor um uso restrito do conceito, desdobrando-o em outros quatro paradigmas. A partir disso, estamos interessados também em entender o lugar desses sujeitos nas lutas coloniais e anticoloniais, assim como na formação das identidades e dos cânones literários nacionais.

Entendemos que queerizar a leitura sobre as donzelas-guerreiras significa contaminar a crítica literária com os estudos queer, especialmente, neste caso, através das considerações de Halberstam (2008) e Mauro Cabral (2006) sobre masculinidades. Além disso, pretendemos também fazer fracassar a crítica literária sobre essas personagens exatamente naquilo que ela tem de autoritária, de colonizadora, de binária e de patologizante. Consequentemente, estamos mais interessados em fazer audíveis essas vidas literárias a partir do que elas têm de próprias, do que em interpretá-las a partir de uma leitura psicanalítica que não só compreende a biologia como destino, como também entende o trânsito entre gêneros como patologia.

Assim sendo, seguindo a Halberstam (2008) e Cabral (2006), consideramos a masculinidade como um dispositivo que interpela a todos os sujeitos e não somente aqueles com falo, o que significa que a masculinidade também pode ser uma parte expressiva das subjetividades de corpos designados sexo-politicamente como femininos. Isso significa também que a masculinidade do homem cisgênero, que é naturalizada e entendida geralmente como parte da natureza, tanto quanto as masculinidades femininas, gays ou transgêneras, normativamente entendidas se não como patologia, pelo menos como desvios, são construídas e agenciadas performativamente a partir de um paradigma, construído em um determinado espaço-tempo, do que significa ser homem. Entendemos, assim, que as masculinidades dissidentes produzem uma história própria que merece ser 
estudada, afastando-as da ideia de subordinação, equívoco, desenvolvimento incompleto, inadaptação, castração, etc.

Os estudos literários sobre donzelas-guerreiras, portanto, ao entenderem os gêneros de forma exclusivamente biológica e binária, reduzindo todas as diversas experiências das donzelas-guerreiras à lei paterna e às mulheres cisgêneras, trabalham com uma ideia de masculinidade e feminilidade essenciais que tem pouca potência crítica diante de experiências de gêneros não normativos. Além disso, essas simplificações da crítica têm invisibilizado os corpos e as vidas literárias que transitam entre os gêneros, uma vez que os entende como uma impossibilidade ontológica.

\section{Perspectivas Queer para as Donzelas-Guerreiras}

A partir de um "presentismo perverso", metodologia queer proposta por Halberstam (2008: 75), estamos interessados em pensar questões atuais, sem, obviamente, projetar concepções anacrônicas em obras e vidas literárias do passado. Seguindo a Mikhail Bakhtin (1997: 370), pretendemos formular novas perguntas às donzelas-guerreiras, sem ignorar o tempo histórico dos escritores, mas também sem encerrar as obras nesse passado.

Pensando o paradigma da donzela-guerreira a partir das duas características que consideramos essenciais, entendemos, então, que há quatro expressões de gênero, significativamente distintas entre si, que podem ser inferidas a partir do que a crítica literária hegemônica tem chamado amplamente de donzelas-guerreiras. Dessa forma, é a partir dessas diferentes vivências que pretendemos não só ler essas personagens, mas também tornar epistemologicamente possível expressões de gêneros invisibilizadas pela crítica literária.

Entendemos, portanto, que nessa constelação literária das donzelas-guerreiras há: "mulheres masculinas", personagens que não foram à guerra e nem viveram como homens; "mulheres guerreiras", personagens que não viveram como homens, mas foram à guerra; "donzelas-guerreiras", personagens que viveram como homens temporariamente, em segredo e foram à guerra; "transgeneridades guerreiras", personagens que viveram sempre que puderam como homens e que foram à guerra. 
É preciso dizer que essa proposta de leitura visa não só pensar as diferenças dentro do que se tem entendido como donzelas-guerreiras, mas principalmente analisar as diferenças dentro de cada uma dessas categorias, o que não tem sido possível quando a crítica tem resumido todas essas expressões ao paradigma das donzelas-guerreiras, da castração, da inveja do falo e de uma feminilidade essencial. Nesse sentido, a partir de Dekker e Pol Lotte (2006), acreditamos que o trânsito entre gêneros é não só um elemento significativo dessas personagens, como também é um dispositivo de leitura. Por isso, organizamos nossas análises a partir do tempo e do significado do trânsito entre gêneros.

As "mulheres masculinas" têm sido lidas como donzelas-guerreiras exclusivamente por fugirem do padrão de feminilidade, expressando uma performatividade de gênero que transgride o que se espera normativamente das mulheres cisgêneras. 0 paradigma da donzela-guerreira, portanto, é tomado aqui de modo amplo e metafórico, onde o "viver como homem" significa uma feminilidade masculina e a "guerra" significa as dificuldades da vida. As mulheres masculinas, portanto, experimentam a masculinidade sem viverem como homens, sem irem à guerra e durante um período indeterminado. Por conta dessa transgressão, as "mulheres masculinas" literárias são normalmente assassinadas. A partir de Halberstam (2008:92), podemos dizer que o desprezo que essas personagens sofrem se deve, principalmente, ao reconhecimento público de uma feminilidade masculina. Esse paradigma literário pode ser pensado, por exemplo, a partir das personagens Luzia e Guidinha do Poço, dos livros Luzia-Homem (1903), de Domingos Olímpio, e Dona Guidinha do Poço (1892), de Manuel de Oliveira Paiva, respectivamente.

As "mulheres guerreiras" têm sido lidas como donzelas-guerreiras porque são corpos entendidos como femininos que vão à guerra; descarta-se, assim, o "viver como homens" como parte desse paradigma. É possível que algumas dessas personagens usem algum acessório do vestuário masculino, no entanto, não o faz para ocultar a feminilidade, mas para facilitar a mobilidade e o conforto durante a guerra, como afirma Fernanda Ribeiro (2011). Após a guerra, aquelas que não morrem, retornam ao papel tradicional de gênero. As mulheres guerreiras, portanto, experimentam uma masculinidade guerreira durante um tempo determinado, o período da guerra, sem deixar, no entanto, de se 
apresentar e serem reconhecidas como mulheres cisgêneras. Podemos pensar esse paradigma a partir, por exemplo, da personagem histórica-literária Anita Garibaldi, através das obras A Guerrilheira (1979), de João Felício dos Santos, e Anita (1999), de Flávio Aguiar. As "donzelas-guerreiras" são corpos entendidos cisnormativamente como femininos que vivem e são reconhecidos socialmente como homens que vão à guerra. Exceto pela família, o trânsito entre gêneros não é conhecido, ao contrário, as outras personagens só o conhecem após a guerra, quando aquelas que não morrem, retornam ao papel tradicional de gênero. São personagens, portanto, que experimentam masculinidades guerreiras sendo reconhecidas como homens, ainda que durante um tempo determinado, o período da guerra. 0 trânsito entre gêneros, assim como o desconhecimento e a "descoberta" sobre ele, portanto, ainda que não definitivo, são partes importantes da narrativa dessas personagens. Nesses casos, a transgressão de gênero é tolerada não só pela excepcionalidade da guerra e pela luta pela pátria, mas também pela excepcionalidade guerreira da personagem. Podemos pensar esse paradigma a partir da personagem literária Joana Xaviel, do conto Uma estória de amor (1956), de Guimarães Rosa, mas também através da personagem histórica-literária Maria Quitéria/Soldado Medeiros, através das obras A Incrível Maria Quitéria (1977), de João Francisco de Lima, e Guerreira Maria (2004), de Sônia Coutinho.

As "transgeneridades guerreiras" são corpos entendidos cisnormativamente como femininos que vivem e são reconhecidos como homens que vão à guerra. 0 trânsito entre gêneros pode ser conhecido ou não, mas quando "descoberto" as personagens mantêm a identidade masculina se não de forma definitiva, ao menos sempre que seja possível ou enquanto lhes interesse. São personagens, portanto, que experimentam masculinidades guerreiras, sendo reconhecidas como homens para além do período e da circunstância da guerra. 0 trânsito entre gêneros, portanto, se aproxima mais de uma compreensão de si do que de uma prática provisória e circunstancial relativa à guerra. Nesses casos, assim como as donzelas-guerreiras, as transgressões, quando descobertas, são toleradas, principalmente, pela excepcionalidade guerreira da personagem, mas também pela excepcionalidade dessas vidas. Assim sendo, acreditamos que a crítica literária, ao ler essas experiências como donzelas-guerreiras, devido a uma impossibilidade ontológica e 
epistemológica, tem não só invisibilizado e colonizado a leitura desses corpos a partir da cisgeneridade, como tem também impossibilitado pensar a transgeneridade como um continuum histórico do qual o trânsito entre gêneros dessas personagens históricas e literárias fazem parte. Para pensarmos esse paradigma podem ser consideradas as personagens históricas-literárias Antônio Erauso, do livro História de la Monja Alférez (1894[2002]), de Catalina Erauso, e Nzinga, do livro A Rainha Ginga (2014), de José Eduardo Agualusa, além da personagem literária Diadorim, do livro Grande Sertão: Veredas (1956), de Guimarães Rosa.

Por fim, estamos interessados também em entender o lugar dessas personagens nas lutas coloniais e anticoloniais, assim como o lugar desses textos na formação das identidades e dos cânones literários nacionais. Nesse sentido, acreditamos, a partir de Mendieta (2017: 167) e Vilalva (2004: 174), que a participação em guerras, a defesa da pátria e a luta exemplar no campo de batalha, assim como também, em alguns casos, a virgindade ou assexualidade, são razões que não só legitimam a vida dessas personagens, como também perdoam as suas transgressões e as transformam em heróis nacionais, o que lhes garante, ainda que marcadas por uma excepcionalidade, uma anomalia, um lugar no cânone literário e na formação das identidade nacionais. Como afirma Mendieta (2017: 167), alguns monarcas chegaram a utilizar donzelas-guerreiras como "propaganda", com o objetivo de afirmar que "até mesmo mulheres estavam desejosas em lutar sob o seu estandarte".

Por conta disso, aos romancistas e historiadores coube uma representação tranquilizadora dessas figuras históricas e literárias, que passava por aproximá-las da tradição das "santas travestidas", garantindo assim que a ordem da sexualidade nunca foi ultrapassada, depois, por fazê-las, após à guerra, retornarem à ordem de gênero através do casamento ou, em último caso, da morte. Os críticos literários, mesmo quando tentaram se afastar dessa tradição, terminaram também por complementá-la, ao reafirmarem a ordem de gênero, seja através da leitura psicanalítica, seja através da impossibilidade ontológica de compreender a transição de gêneros fora dos modelos criados para hierarquizá-los. 
Isto posto, a priori, inferimos que as "mulheres masculinas" são personagens contra a nação e por isso são punidas com a morte, assim como são afastadas do cânone literário e da identidade nacional. Enquanto isso, as "mulheres guerreiras" e as "donzelas guerreiras" são personagens nacionais que fazem parte do cânone e da identidade nacional, uma vez que retornam aos papeis tradicionais de gênero e sexualidade após a excepcionalidade da guerra. Por fim, as "transgeneridades guerreiras" são personagens nacionais que fazem parte do cânone e da identidade nacional, principalmente porque a crítica literária tem se empenhado, contra o próprio texto, em simplificar e/ou silenciar as transgressões que a literatura propositalmente não se propõe a resolver.

\section{NOTAS}

${ }^{1}$ Estamos utilizando o " $\mathrm{x}$ " no lugar dos artigos feminino e masculino como uma forma de não determinar $a$ priori o gênero dessas personagens históricas. Afinal, um dos objetivos desse texto é repensar, a partir das Teorias Queer, a leitura dimórfica da crítica sobre esses sujeitos. Nesse sentido, colabora com nossa perspectiva o fato da maior parte dessas personagens não só terem transitado entre os gêneros, como também terem vivido sob nomes masculinos e femininos.

2 De acordo com Jan Kott (Gutiérrez 2013: 101), durante a Idade Média, o tema de "mulheres travestidas" estava dividido em três linhas diferentes, que em alguns momentos convergiam e contavam com grande aceitação de público: a vertente hagiográfica das santas católicas travestidas, a vertente cavalheiresca das donzelas-guerreiras e a vertente ligada à educação, onde o trânsito para a masculinidade garantia o acesso a instituições de ensino.

${ }^{3}$ Cisgênero(a) é a pessoa que se identifica com o gênero que lhe foi designado em seu nascimento. Segundo Hailey Kaas (2012), cisgênero(a) é a pessoa que designada "homem" ou "mulher", se sente bem com isso e é percebida e tratada socialmente (medicamente, juridicamente, politicamente) como tal. Consequentemente, a pessoa transgênera é aquela que não se identifica com o gênero que lhe foi designado no nascimento.

N. 39 - 12/ 2018 | 91-108 - ISSN 2183-2242 | http:/dx.doi.org/10.21747/21832242/litcomp39a6 


\section{Bibliografia}

Agualusa, José Eduardo (2015), A Rainha Ginga, Rio de Janeiro, Foz.

Aguiar, Flávio (1999), Anita, São Paulo, Boitempo.

Amaro, Ana Maria (1992), "Fá mok lan / A donzela que foi a guerra”, Revista da Faculdade de Ciências Sociais, no. 6, 51-76.

Bakhtin, Mikhail (1997), Estética da criação verbal, São Paulo, Martins Fontes.

Batista, Edilene (2010), "Do poema medieval anônimo da donzela que vai à guerra aos cordéis nordestinos: um estudo da donzela guerreira”, in Ángel Christian Luna Alfaro y José Luís Montero Badillo (eds.), Sexualidad y poder: tensiones y tentaciones desde diferentes tiempos y perspectivas históricas, México, Eumed, 153-166.

-- (2012), “Diadorim, Maria Moura e Monja Alférez: faces diferenciadas do mito da donzela guerreira", in Libro de Actas del I Congreso Internacional de Comunicación y Género, Sevilla, Editorial Madrid, 275-289.

-- (2016), "Análise comparativa entre as donzelas guerreiras Diadorim e Monja Alférez", Interdisciplinar, vol. 25, 157-168.

Cabral, Mauro (2006), “La paradoja transgénero”, Boletín Electrónico del Proyecto Sexualidades, salud y derechos humanos en América Latina, n.ํㅜ 18, 97-104.

Connell, Raewyn (2003), Masculinidades, México, UNAM.

Coutinho, Sonia (2004), Guerreira Maria: presença de Maria Quitéria, Rio de Janeiro, Dublin.

Dekker, Rudolf / Lotte, Van de Pol (2006), La doncella quiso ser marinero: travestismo femenino en Europa (siglos XVII-XVIII), Madrid, Siglo XXI.

Drummond de Andrade, Carlos (1973), "Mulher vestida de homem”, in Menino Antigo, Rio de Janeiro, José Olympio, 179-180.

Erauso, Catalina (2002), Historia de la Monja Alférez, Catalina de Erauso, escrita por ella 
misma, Madrid, Cátedra.

Freitas, Norma (2012), "O solar e o lunar em Luzia-Homem: a trajetória da donzelaguerreira", Revista de linguagem do cinema e do audiovisual, vol.1, n.ํㅡ. 15-32.

Galvão, Walnice (1998), A donzela-guerreira: um estudo de gênero, São Paulo, Senac.

-- (2002), “Metamorfoses da donzela-guerreira”, Dialogia, vol. 1, 21-26.

-- (2016), "De Frida Kahlo à Donzela Guerreira”, <https://bit.ly/2tJQfgq> (último acesso em 26/12/2018).

García Surrallés, Carmen (1989), “La doncella que fue a la guerra: romance y cuento", Tavira, n.ㅇ 6, 5-24.

Gutiérrez, José (2010), “Travestismos femeninos: escritura y mujer frente al poder patriarcal", in Actas del XVI Congreso de la Asociación Internacional de Hispanistas: nuevos caminos del hispanismo, Coord. Pierre Civil \& Françoise Crémoux, Iberoamericana, 1-8.

-- (2013), Del travestismo femenino: realidad social y ficciones literarias de una impostura, Vigo, Academia del Hispanismo.

Halberstam, Jack (2008), Masculinidad Femenina, Barcelona, Egales.

Kaas, Hailey (2018), “O que são pessoas cis e cissexismo?” <https://bit.ly/2LZoczK> (último acesso em 11/12/2018).

Lima, João Francisco (1977), A incrível Maria Quitéria, São Paulo, Nova Época.

Lugarinho, Mário (2017), “Ordem, gênero e transgressão em A senhora de Pangim, de Gustavo Barroso", in Via Atlântica, n.ํㅜ 33, 253-272.

Maia, Helder Thiago (2013), "Retratos da sexualidade: Uma Análise das Obras 'La Monja Alférez' de Juan Pérez de Montalbán e 'Historia de la Monja Alférez, Catalina de Erauso, escrita por ella misma' de Catalina de Erauso", in Revista Feminismos, vol. 1, n. 3, 72-87.

Meirelles, Cecília (1960), “Uma antepassada da 'donzela-guerreira'”, in Estudos e ensaios folclóricos em homenagem a Renato Almeida. Rio de Janeiro, Ministério das Relações Exteriores, 53-58. 
Mendieta, Eva (2017), “En busca de Catalina de Erauso: identidades en conflicto en la vida de la Monja Alférez", Asparkia, n. 30, 163-174.

Olímpio, Domingos (1993), Luzia-Homem, São Paulo, Moderna.

Oliveira, Valdeci (2001), Figurações da donzela-guerreira nos romances Luzia-Homem $e$ Dona Guidinha do Poço. Dissertação de Mestrado em Teoria e História Literária, Universidade Estadual de Campinas Campinas, UNICAMP, $154 f$.

Paiva, Manuel de Oliveira (2000), Dona Guidinha do Poço, São Paulo, Ática.

Ribeiro, Fernanda (2011), Anita Garibaldi coberta por histórias, São Paulo, Cultura Acadêmica.

Rocha Monsalve, Victor (2005), "Cuerpos disidentes y travestismo en América Colonial: Catalina de Erauso o la disputa por la identidad", in X Jornadas Interescuelas, Universidad Nacional del Litoral, Rosario, 1-14.

Rosa, Guimarães (1956), "Uma estória de amor", in Corpo de baile, Rio de Janeiro, José Olympio, 83-144.

-- (1994), Grande Sertão: Veredas, São Paulo, Editora Nova Aguilar.

Santos, João Felício (1987), A guerrilheira: o romance da vida de Anita Garibaldi, São Paulo, Círculo do Livro.

Silva, Anabela (2010), A donzela guerreira: confluências literárias, Dissertação de Mestrado, Faculdade de Letras do Porto, Porto, $118 f$.

Silva, Eliana (2013), Atualizações e Ressignificações do Mito da Donzela Guerreira: Uma análise Comparada dos romances Papisa Joana (Donna Wolfolk Cross) e Memorial de Maria Moura (Rachel de Queiroz), Dissertação de Mestrado, Universidade Federal do Ceará, Fortaleza, 156f.

Silva, Márcio (2017), “0 mito da donzela guerreira na narrativa de Alina Paim”, Revista Fórum Identidades, vol. 24, 219-233.

Sussekind, Flora (1984), Tal Brasil, qual romance?: uma ideologia estética e sua história: o 
naturalismo, Rio de Janeiro, Achiamé.

Vasconcelos, Vania (1998), A donzela guerreira e a descostura irônica do novo romance histórico em Viva o povo brasileiro, Dissertação de Mestrado, Universidade Federal do Ceará, Fortaleza, 194f.

-- (2010), “A donzela guerreira na literatura brasileira”, in Regina Pamplona Fiúza (coord.), A mulher na literatura: criadora e criatura, Fortaleza, Academia Cearense de Letras, 245257.

Vasvári, Louise (2006), “Queering the donçella guerrera”, Calíope, vol. 12, n. 2, 93-117.

Vilalva, Walnice (2004), Marias: estudo sobre a donzela-guerreira no romance brasileiro, Tese de Doutorado em Teoria e História Literária, Universidade Estadual de Campinas (UNICAMP), $193 \mathrm{f}$.

Helder Thiago Maia é pós-doutorando em Literaturas Africanas de Língua Portuguesa na Universidade de São Paulo (USP), é pesquisador do grupo CUS - Cultura e Sexualidade (UFBA) e editor da revista Periódicus. Autor dos livros $O$ devir darkroom e a Literatura Hispano-Americana (2014) e Cine(mão): espaços e subjetividades darkroom (2018). 